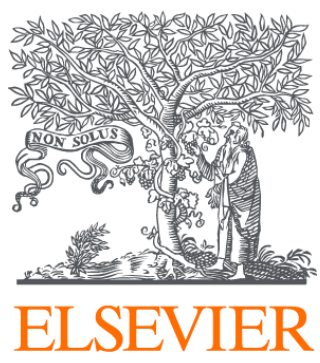

Since January 2020 Elsevier has created a COVID-19 resource centre with free information in English and Mandarin on the novel coronavirus COVID-

19. The COVID-19 resource centre is hosted on Elsevier Connect, the company's public news and information website.

Elsevier hereby grants permission to make all its COVID-19-related research that is available on the COVID-19 resource centre - including this research content - immediately available in PubMed Central and other publicly funded repositories, such as the WHO COVID database with rights for unrestricted research re-use and analyses in any form or by any means with acknowledgement of the original source. These permissions are granted for free by Elsevier for as long as the COVID-19 resource centre remains active. 


\section{Health and social justice}

Jennifer Prah Ruger

4 years into the new millennium, the health of the world's citizens is remarkably uneven. A child born today in Japan, for example, can expect to live to age 82 years on average, whereas it is unlikely that a newborn infant in Zimbabwe will reach his or her 34th birthday. ${ }^{1}$ Over several decades, scientific progress has expanded our ability to improve human health, and many regions of the world have achieved significant health gains. Yet extreme deprivation in health is still widespread. Resolving this predicament of major health improvement in the midst of deprivation is one of the greatest global challenges of the new millennium.

These health disparities exist in a world that is becoming more closely linked in all domains, including health. The rapid spread and quick containment of severe acute respiratory syndrome (SARS) demonstrates the interconnectedness of our world as well as any recent health phenomenon. The same trend can be seen with HIV/AIDS and the potential to link solutions and best practices studied in one part of the globe with persistent health problems in another.

In the midst of such rapid global change and persistent health disparities, we need to revisit and underscore the moral and philosophical foundations for health improvement activities-to give them more forceful grounding and solidity. In this essay, I briefly survey some traditional philosophies of justice and health care. I then offer an alternative view of justice and health that is rooted in Amartya Sen's capability approach and Aristotle's political theory, and discuss the implications of this approach for health improvement across the globe.

\section{Philosophical foundations}

Theories of social justice (eg, fair and equitable treatment of people) have typically focused on justifying health care (medicine and public health) as a special social good. Rationalising greater equality in health care is typically the point of departure for most approaches to medical ethics (bioethics), even for approaches that include health assessment. In general, less attention has been paid to universal concerns of social justice with respect to health itself. This essay focuses on the question of why health, as opposed to health care, has special moral importance for social justice in health improvement activities. I also analyse the implications of equity in health and health care.

Philosophical theories have been reluctant to give health (by contrast with health care) special moral importance for at least one primary reason: they share the assumption that health is not an appropriate focal variable for assessing social justice. Egalitarian theories, for example, "propose that persons be provided an equal distribution of certain goods such as health care, but all prominent egalitarian theories of justice are cautiously formulated to avoid making equal sharing of all possible social benefits a requirement of justice". ${ }^{2}$ Utilitarian theories, although consequentialist (eg, assessing states of affairs or actions in terms of their consequences), focus on the space of "utilities" (satisfaction, desire fulfilment, preference), ${ }^{3}$ whereas communitarian approaches focus on community values, ${ }^{4}$ rather than on health itself. Liberal theories of justice are disinclined to focus on health because, as John Rawls purports in his book, A theory of justice, natural goods like health are not included as social values or social primary goods (eg, "liberty and opportunity, income and wealth and the bases of self-respect") that are "things that every rational man is presumed to want." ${ }^{5} \mathrm{He}$ adds that "health and vigor, intelligence and imagination, are natural goods; although their possession is influenced by the basic structure, they are not so directly under its control."5 Thus, according to Rawls, health is not one of the social primary goods that should be "distributed equally unless an unequal distribution of any, or all, of these values is to everyone's advantage." Although he discusses basic health care later in his book, Law of Peoples, Rawls does not include health in the list of social primary goods subject to distributive principles.

Norman Daniels argues that, "health is an inappropriate object, but health care, action which promotes health, is appropriate." ${ }^{6} \mathrm{He}$ and others emphasise that ". . . a right claim to equal health is best construed as a demand for equality of access or entitlement to health services ... ", ${ }^{6}$ and note that a "'right to health' embodies a confusion about the kind of thing which can be the object of a right claim". ${ }^{6}$ Such reasoning illustrates the strong bias against health as a focal variable in current ethical theory.

\section{A capability view of health}

A contrasting argument is that health has special moral importance because of its status as an end of political and societal activity. According to Aristotle, society's obligation to maintain and improve health rests on the ethical principle of "human flourishing" ${ }^{7-11}$ - the ability to live a flourishing, and thus healthy, life. ${ }^{7-11}$ Flourishing and health are inherent to the human condition. ${ }^{7-11}$ Indeed, certain aspects of health sustain all other aspects of human flourishing because, without being alive, no other human functionings are possible, including agency, the ability to lead a life one has reason to value. ${ }^{12-14}$ It can be argued, therefore, that public policy should focus on the ability to function, and that health policy should aim to maintain and improve this ability by meeting health needs..$^{15,16}$ This view values health
Lancet 2004; 364: 1075-80 Department of Epidemiology and Public Health, School of Medicine, Yale University, New Haven, CT 06520, USA (J P Ruger PhD)

Correspondence to: Dr Jennifer Prah Ruger jennifer.ruger@yale.edu

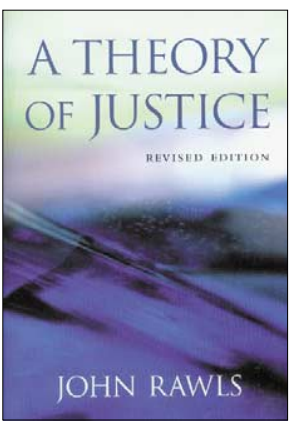




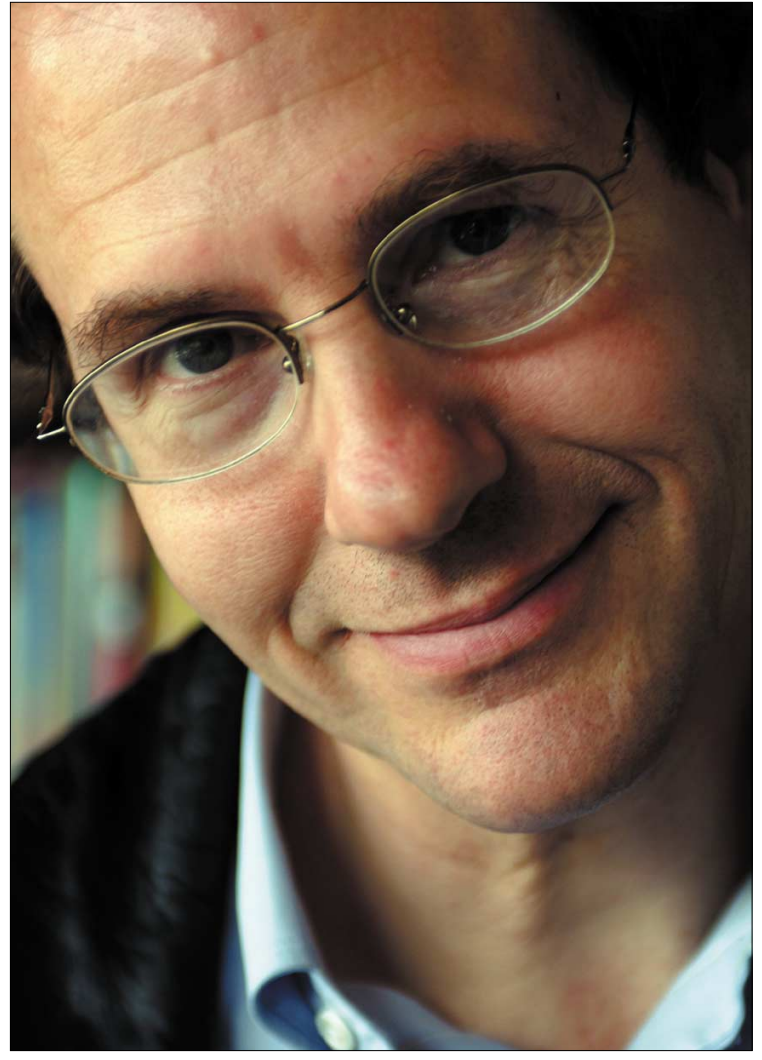

Cass Sunstein

intrinsically and more directly than solely "instrumental" social goods, such as income or health care. It gives special moral importance to health capability: an individual's opportunity to achieve good health and thus to be free from escapable morbidity and preventable mortality. ${ }^{15,16}$

This line of reasoning-focusing on human capability-contrasts with the idea that health care is special because of its impact on equality of opportunity. ${ }^{6}$ It also differs from the utilitarian view that health care is important for maximising the sum total of utilities and from procedural views that focus on guaranteed due process. The distinction between these approaches is rooted in the different points of focus that these theories support. Capability describes what individuals are able to do and be, offering a realistic sense of their freedom to pursue the lives they have reason to value. Thus, society is morally obligated to attach importance to averting or ameliorating loss in physical functioning even if a person's subjective utility assessment is quite high and even if opportunity of employment is still possible. In short, a person's ability to function, rather than to be happy or to have employment opportunities, should be the gauge for assessing public policy.

A capability view of health also includes human agency (ie, people's ability to live a life they value). ${ }^{17,18}$
Although health directly affects the ability to exercise agency, agency influences health as well. For example, the ability to lead the life one values can improve one's mental health or well-being. Conversely, the ability to make unhealthy choices can degrade one's health status. Enabling individuals to exercise their agencyboth individually and collectively-enables them to prioritise and decide which health domains they value most (eg, to trade-off quality and quantity of life) and to choose what health services they would like to consume (eg, making choices among treatment options).

The exercise of human agency can occur at both the individual and collective levels. Individual agency is important in decisions about health habits and risks, lifestyle, individual priorities, and decisions about treatment options. Collective agency is more important at the policy level, where open discussion and collective decision-making influence policy and resource allocation. This relates to the "process" aspect of freedom in the capability approach. ${ }^{14}$

\section{Policy implications}

There are several sets of policy implications related to a capability view of health. First, the distinction between a capability approach to health and other well-known ethical approaches has implications for assessing social inequalities and for evaluating the effects of social policy on broader health determinants. Health care is not the only health determinant, as Michael Marmot and his colleagues' work has shown, ${ }^{19}$ and one must not assume that more and better health care is all that is needed to improve health. The main impact of health care may depend on the type of care and sometimes on other factors. This places both health and health policy in a larger policy context and requires a greater understanding of social justice. ${ }^{15,16}$ Thus, health and its determinants must be valued against other social ends in a broader public exercise of policy priorities. This exercise should be inclusive and democratic and should represent a process of public reasoning about the ends and means of public policy more broadly and about health policy specifically.

Second, although health care is only one of many health determinants, its influence on health should not be denied. Thus, health care is important and therefore, special, due to its role in influencing health and it must be socially guaranteed. It must be socially guaranteed in a manner that is consistent with improving health overall and reducing health inequalities that are attributable to health care-not in terms of equality in health care delivery (equal amounts or types), irrespective of health consequences.

Third, a capability view of health does not specify which type of health care (eg, a list or basic benefits package) should be guaranteed and to what level. Rather, it recognises the need for further specification through a democratic process that combines both 
procedural and substantive principles. Substantively, Sen's notion of "basic capabilities" provides guidance since this formulation generally implies that societal efforts be made to bring each individual's health functioning as close as possible to (or above) a certain level of minimal normal functioning (in so far as an individual's circumstances permit). "Basic capabilities" include the ability to avoid escapable morbidity and premature and preventable mortality. Premature mortality implies placing special emphasis on efforts to avert deaths from preventable causes that do not allow individuals to live a life of normal length (eg, a child dying of AIDS). On the question of how much priority should be given to society's worst-off individuals, this view promotes the use of "public reasoning" to forge a compromise between strict maximisation and prioritisation.

Fourth, this "process aspect" of freedom in the capability approach has implications for how healthrelated policy is made. It emphasises an individual's ability to participate in broad public-policy decisionmaking (eg, in prioritising between environmental and health care programmes) and in health policy decisionmaking (eg, in prioritising domains of health and health care for resource allocation). A democratic process can help define a comprehensive package of health benefits to which all should have equal access, and it can help prioritise different types of health care in efforts to maintain and improve health with the fewest possible resources. Such a process is not merely instrumental, however, since its justification lies in the concept that individuals should have the capability to participate in decision-making that affects them, such as about the goods and services that society will guarantee to them.

Fifth, the equity implications of access to those goods and services cannot be separated from the equity implications of financing them, because the capability principle requires that resources be allocated on the basis of medical need, not ability to pay. The costs of health-related goods and services directly affect health by reducing the demand for necessary health care or by increasing consumption of unnecessary care. Leaving people vulnerable to economic barriers therefore would fail to reduce deprivations in health. Additionally, the uncertainty of health need, the catastrophic costs of medical care, and the risk-averse nature of individuals places risk pooling (eg, through insurance) at the centre of health-care financing. ${ }^{20}$ An expensive medical event can prevent access to health care or be a primary cause of financial ruin. From a capability point of view, "protective security", ${ }^{14}$ through health insurance, is a necessary safety net. And the economic burden of health care should be justly shared by all through the redistribution of funds from the well to the ill and the rich to the poor, using progressive financing and community rating. ${ }^{21}$
Sixth, one of the most difficult tasks in applying an ethical framework that values health intrinsically is the conceptualisation and measurement of health and inequalities in its many domains. There are many approaches to measuring health equity. As Sudhir Anand and colleagues have shown ${ }^{22}$ the choice depends on numerous considerations, ranging from health domains to the weights attached to those domains. ${ }^{22}$ Another consideration is the choice of groups for

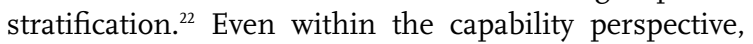
one would need to determine what set of inequality measures would be most appropriate for a given exercise, although certain types of inequality assessment-for example, a goal of complete "health equality" (levelling down to lowest common denominator)-have less appeal than others. And certain health equity evaluations-for example, deciding how much priority to give the "worst-off"-will undoubtedly require public reasoning about values imbedded in the health equity concept. Although the capability view of health does not come down on an exact formula for judging inequalities in health, Sen has noted the potential use of "partial ordering" (eg, ordering some alternatives as opposed to ordering them all) of health states for assessing relative inequalities. In a collective exercise, incomplete theorisation may facilitate evaluation in health policy. ${ }^{15,16,23}$

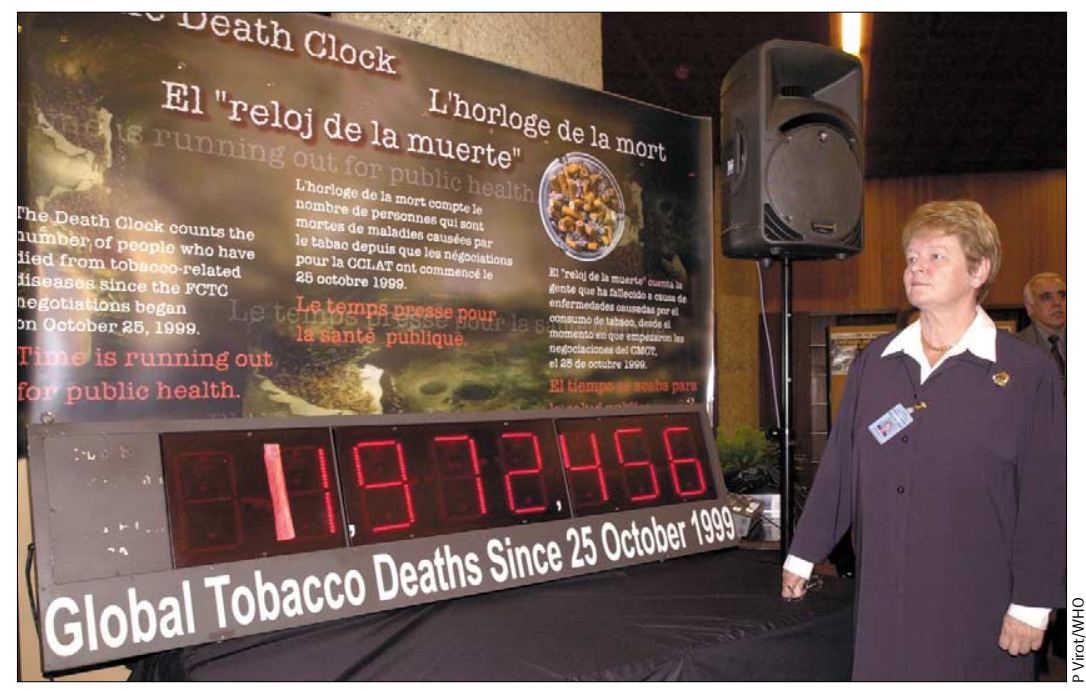

Gro Harlem Brundtland at the Framework Convention on Tobacco Control, 2002

\section{Incompletely theorised agreements}

Incomplete theorisation is useful to a theory of health and social justice because it provides a framework for understanding collective decision-making on human goods that are plural and indistinct (such as health and inequality), and allows individuals to take divergent paths to a common, though often partial, agreement. It describes how people with divergent, even opposing, views on health, equity, and health-policy issues might 
reach agreement in specific situations and thus generate health-policy decisions that are legitimate and stable and reflect mutual respect. ${ }^{15,16,23}$ The method of reaching agreement described here is called incompletely theorised agreements, developed by Cass Sunstein, ${ }^{24}$ and it holds promise for health-policy decision-making at several levels. ${ }^{15,16,23}$

An incompletely theorised agreement is one that is not uniformly theorised at all levels, from high-level justifications to low-level particulars. It complements and extends the capability approach by providing a framework for operationalising the capability approach at three or more levels. The first level is the conceptual level, which specifies the valuable functionings that constitute human flourishing and health. The second level is the policy level, which specifies policies and laws. The third level is the intervention level, which specifies actions in particular cases and decisions about medical treatments, public-health interventions or social services. This framework constitutes three different types of incompletely theorised agreements: incompletely specified agreements, incompletely specified and generalised agreements, and incompletely theorised agreements on particular outcomes.

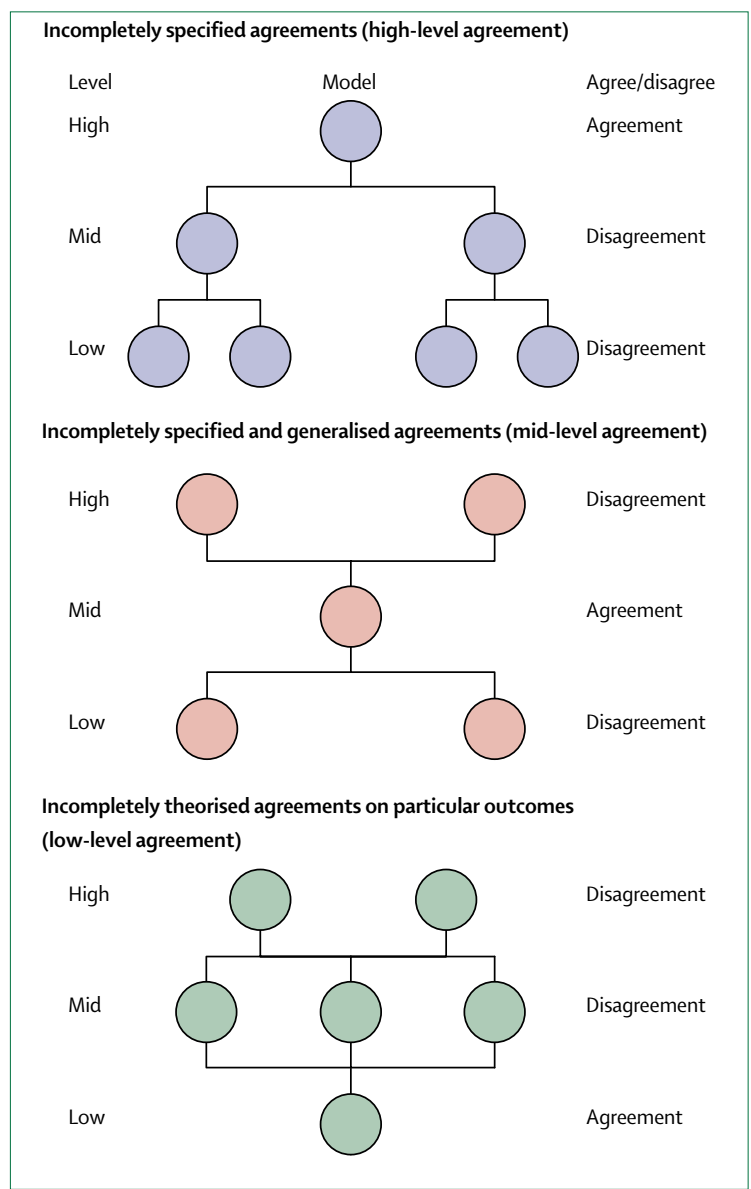

Models of incompletely theorised agreements

\section{Incompletely specified agreements}

The first type of incompletely theorised agreement occurs when there is agreement on a general principle but sharp disagreement about particular cases. People who accept a general principle, such as the illegality of murder, need not agree on the application of this principle to particular cases. For example, they could disagree about whether abortion should be classified as murder. ${ }^{24}$ This first type of agreement is closely connected to Rawls' “overlapping consensus". In the health-policy context, citizens might agree on costeffectiveness as a general principle, but also agree that $\beta$ interferon, a drug that helps some individuals with multiple sclerosis, should be provided to such patients even though its cost per quality-adjusted life year (QALY) ranges from US\$35000 to $\$ 20$ million, or agree that kidney dialysis should be provided despite its exorbitant cost for relatively small improvements in health-related quality of life.

\section{Incompletely specified and generalised agreements}

The second type of incomplete theorisation occurs when people agree on a mid-level principle but disagree about both the more general theory that accounts for it and outcomes in particular controversies. Here, Sunstein argues that the connections between the general theory and mid-level principles and also between specific cases and mid-level principles are unclear. ${ }^{24}$ In the health policy context, citizens might agree that all should have access to life saving interventions, but disagree on both the underlying theoretical doctrine for this view and on whether all life saving interventions at all stages of life should be provided.

\section{Incompletely theorised agreements on particular outcomes}

This third type of incompletely theorised agreement describes how people reach agreement on particular public policy options. In this model, agreement is reached on low-level principles that are not necessarily derived from a particular high-level theory of the right or the good. In fact, the same low-level principles may be compatible with more than one high-level theory because people may disagree on or not fully understand a relatively high-level abstraction while agreeing on "a point of less generality".

In such contexts, people "can know that $\mathrm{X}$ is true without entirely knowing why $\mathrm{X}$ is true." ${ }^{24}$ The emphasis here is on not knowing something entirely-completely theorising it from high to low levels. People might agree, for instance, that governments should prevent famine, eradicate malaria or tuberculosis, and not condone genital mutilation, but they might not know exactly why they hold such beliefs. This reasoning might be both moral and reasonable, but the deliberators might not explicitly state that their decision is derived from an 
underlying theory, even though it certainly might be informed by a lower level conception of the good life they articulated. This aspect of the framework complements the capability approach's emphasis on partial agreements and on identifying workable solutions that make the most of consensus and that can be "based on the contingent acceptance of particular provisions, without demanding complete social unanimity". ${ }^{14}$

Thus, in matters of public decision-making about health and health policy, the incomplete theorisation framework is useful in furthering a capability approach to health. ${ }^{15,16}$ First, health, and thus health capabilities, is a multidimensional concept about which different people might have different, and sometimes conflicting, views, especially at an epistemological level. This heterogeneity makes complete theorisation difficult to achieve. Second, there might be no view of health, and thus health capabilities, that is ideal for all evaluative purposes; therefore, the pragmatism of the incomplete ordering of the capability approach and the incompletely theorised agreement on that ordering of the incomplete theorisation approach allows for reasoned public-policy decision-making in the face of multiple, and even conflicting, views on health. Third, there could be no single quantitative scale for comparing health capabilities and the inequalities in them; deviations in individuals' capability for functioning may occur in different domains of health capability that may not be quantifiably comparable. For example, one cannot quantifiably compare one individual's inability to hear or see with another's inability to bear children or to walk. These reductions in individuals' capabilities for functioning are qualitatively different and different people will have widely diverging views on which functional capability reduction is better or worse than the other. Thus, a framework for articulating and agreeing upon a conception of health functioning for prioritising health goods and services is required. Given the demands of policy evaluation in particular contexts, the combined approaches also allow reasoned agreement on central aspects of health and their respective capabilities without requiring people to agree on non-central aspects or fully understand their beliefs.

\section{Global health institutions}

What do these philosophical arguments imply for global health institutions? Global health institutions have important roles in the implementation of a capability approach to health because they can help generate and disseminate the knowledge and information required to reduce health disparities. For example, they can help create new technologies (eg, an HIV/AIDS vaccine), transfer, adapt, and apply existing knowledge (eg, prevention of malaria transmission), manage knowledge and information (eg, statistics on inequality in infant/child mortality and best practices), and help

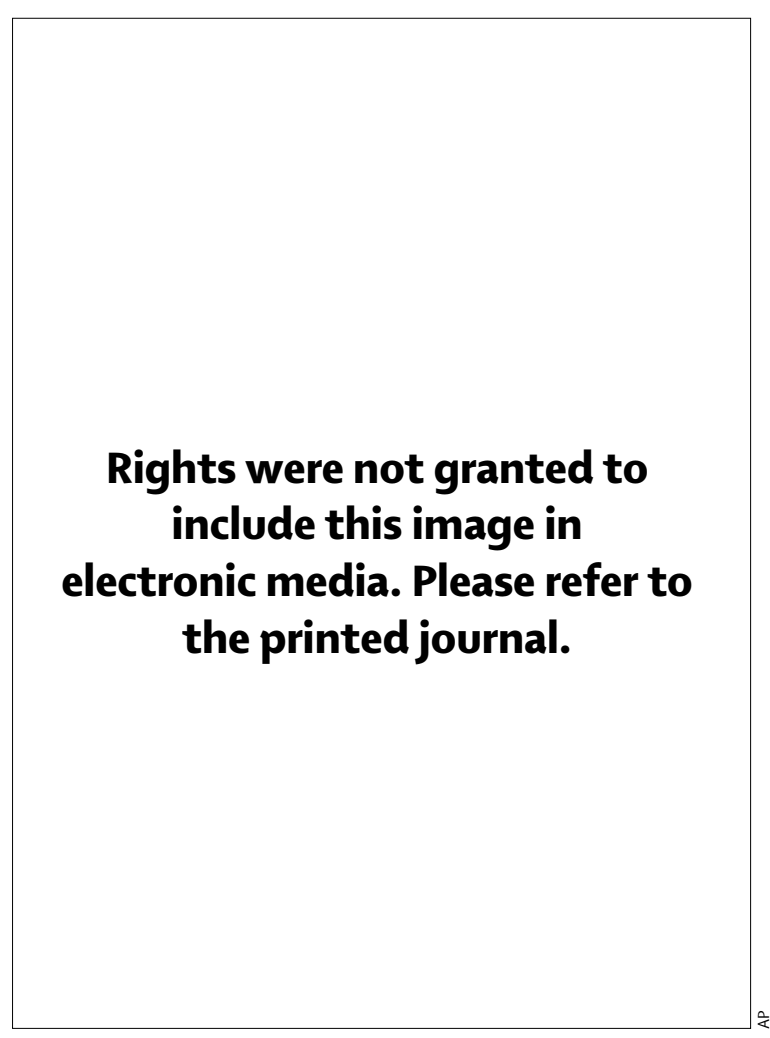

countries develop information and research capacity ${ }^{25,26}$ (eg, health surveillance and information systems).

Global health institutions can also empower individuals and groups in national and global forums. Indirectly, they can push for greater citizen participation in health-related decision-making in developing countries, both within (eg, in determining resource allocation) and outside the health sector. Since greater empowerment in the health sector is built on more democratic governance overall, reform of state and social institutions may be needed to achieve these goals. And encouraging the political will for public action to reduce health inequalities will be essential. Global health institutions, particularly WHO and World Bank, can help governments improve the public administration needed to deliver quality health care to all. They should also give individuals and groups a greater voice in national and international forums and programmes, such as a health-sector loan or an international tobaccocontrol agreement, and engage more with civil society and the private sector.

Global health institutions can also provide technical assistance, financial aid, and global advocacy to support the development of equitable and efficient health systems and public health programmes. This assistance can occur at the macro level (eg, standardising diagnostic categories) or the micro level (eg, providing antiretroviral medicines for AIDS patients). Some global health institutions (eg, WHO) have tended to organise 
around specific diseases (HIV/AIDS, malaria, tuberculosis, polio, and SARS), whereas others such as the World Bank have favoured sector-wide initiatives. Although both perspectives are valuable, greater coordination among policy actors is essential. Such efforts should build on existing work such as the Rockefeller Foundation's global health equity initiative. ${ }^{27}$

Finally, global health institutions should be linked to other institutions in a coordinated and integrated way. The Framework Convention on Tobacco Control (FCTC), for example, recognises the importance of integrating public policies into a comprehensive set of health improvement strategies. Through the FCTC, ministries of health and health-related associations, such as physician groups, are united with ministries of finance, economic planning, taxation, labour, industry, and education as well as with citizen groups and the private sector, to create a multisectoral national and international tobacco-control effort. The FCTC represents a growing trend in development policy toward an alternative paradigm that is broad, integrated, and multifaceted. ${ }^{14,17,28-31}$ Adopting a multifaceted and integrated approach to health improvement requires rejecting a narrow view of health and its determinants and the philosophical foundations that support such a view.

\section{Acknowledgments}

I thank Amartya Sen, Sudhir Anand, Michael Marmot, and participants in the workshop on Rights, Dignity, and Inequality at Trinity College, Cambridge, UK, for helpful comments. I also thank Washington University School of Medicine and Center for Health Policy for support. J P Ruger is supported in part by a Career Development Award (grant 1K01DA016358-01) from the US National Institutes of Health.

References

1 United Nations Development Programme. Human development reports, 2003.http://www.undp.org/hdr2003/indicator/ indic_70_1_1.html (accessed Oct 27, 2003).

2 Beauchamp TL, Childress, JF. Principles of biomedical ethics. 4th edn. New York: Oxford University Press, 1994.

3 Gold MR, Siegel JE, Russel LB, Weinstein MC. Cost-effectiveness in health and medicine. New York, NY: Oxford University Press, 1996.

4 Emanuel EJ. The ends of human life. Cambridge, MA: Harvard University Press, 1991

5 Rawls J. A theory of justice. Cambridge, MA: Harvard University Press, 1971.

6 Daniels N. Just health care. New York: Cambridge University Press, 1985.

7 Aristotle. The Nicomachean ethics. Translated by Welldon JEC Amherst, NY: Prometheus Books, 1987.
8 Nussbaum MC. Nature, function, and capability: Aristotle on political distribution. In: von Gunther Patzig H. Aristoteles politik. Gottingen: Vandenhoeck and Ruprecht, 1990.

9 Nussbaum MC. The good as discipline, the good as freedom. In: Crocker D, ed. The ethics of consumption and global stewardship. Lanham, MA: Rowman and Littlefield, 1998: 312-41.

10 Nussbaum MC. Human functioning and social justice: in defense of Aristotelian essentialism. Polit Theory 1992; 20: 202-46.

11 Aristotle. The politics. Translated by Lord C. Chicago, IL: University of Chicago Press, 1994.

12 Sen AK. Commodities and capabilities. Amsterdam; North-Holland, 1985.

13 Sen AK. Inequality reexamined. Cambridge, MA: Harvard University Press, 1992.

14 Sen AK. Development as freedom. New York: Knopf, 1999.

15 Ruger JP. Aristotelian justice and health policy: capability and incompletely theorized agreements. PhD thesis, Harvard University, 1998.

16 Ruger JP. Social justice and health policy: Aristotle, capability, and incompletely theorized agreements- lecture given at Harvard University, 1997.

17 Ruger JP. Health and development. Lancet 2003; 362: 678.

18 Ruger JP. Combating HIV/AIDS in developing countries. BMJ 2004; 329: 121-22.

19 Marmot MG, Bobak M, Davey Smith G. Explorations for socia inequalities in health. In: Amick BC, Levine S, Tarlov AR, Chapman D, eds. Society and health. London: Oxford University Press, 1995.

20 Ruger JP. Catastrophic health expenditure. Lancet 2003; 362: 996-97.

21 VanDoorslaer E, Wagstaff A, Ruttern F, eds. Equity in the finance and delivery of health care: an international perspective. New York: Oxford University Press, 1993.

22 Anand S, Diderichsen F, Evans T, Shkolnikov VM, Wirth M. Measuring disparities in health: methods and indicators. In: Evans T, Whitehead M, Diderichsen F, Bhuiya A, Wirth M, eds. Challenges inequities in health: from ethics to action. London: Oxford University Press, 2001.

23 Ruger JP. Health, health care, and incompletely theorized agreements, mimeographed. Harvard University, 1995.

24 Sunstein C. Incompletely theorized agreements. Harvard Law Review 1995; 108: 1733.

25 Horton R. North and South: bridging the information gap. Lancet 2000; 355: 2231-36.

26 Chen LC, Berlinguer G. Health equity in a globalizing world. In: Evans T, Whitehead M, Diderichsen F, Bhuiya A, Wirth M, eds. Challenges inequities in health: from ethics to action. London: Oxford University Press, 2001.

27 The Rockefeller Foundation. Program in health equity. http:// www.rockfound.org/display.asp?Context=3\&SectionTypeID= $18 \&$ Preview $=0 \& A R C u r r e n t=1$ (accessed Oct 10, 2003).

28 Stiglitz JE. An agenda for development in the twenty-first century. In: Pleskovi B, Stiglitz JE, eds. Annual World Bank conference on development economics 1997. Washington, DC: World Bank, 1998.

29 Wolfensohn JD. A proposal for a comprehensive development framework. Washington, DC: World Bank mimeograph, 1999.

30 Rodrik D. Making openness work: the new global economy and the developing countries. Washington, DC: Overseas Development Council, 1999.

31 Ruger JP. Changing role of the World Bank in global health. Am J Public Health (in press). 